\title{
El ocaso de los dioses de la prosperidad después del TLC y en pleno bicentenario. Neoliberalismo, desigualdad y el ascenso de los populismos en Costa Rica
}

Gustavo Cabezas-Barrientos *

https://orcid.org/0000-0003-2859-1554

\section{Resumen}

A las puertas del bicentenario de la independencia, el modelo económico que se ha asumido como nación, no parece cumplir las promesas que ha hecho al menos no para la mayoría, sino para un pequeño grupo. A pesar de las múltiples pruebas de la necesidad de un Estado que reactive la economía, ya que el mercado carece del interés, y la necesidad de hacer un mejor reparto de la riqueza; la población no tiene claro en qué consistieron las reformas neoliberales en la década de 1980 y su responsabilidad en el actual Estado social.

Estas reformas han generado varias crisis: económica, institucional, migratoria y de representación política, que han erosionado la institucionalidad y representan el ascenso de grupos que se inclinan a los populismos, en el caso de Costa Rica, en grupos conservadores; donde paradójicamente se añora el Estado de bienestar y se vota por aquellos partidos que prometen su recuperación mediante elementos antidemocráticos y violentando derechos humanos. Este ensayo ${ }^{1}$ desarrolla el tema descrito.

Palabras clave: Crecimiento económico, desarrollo, Estado social de derecho.

* Máster en Criminología de la Universidad Estatal a Distancia (UNED), de Costa Rica. Licenciado y bachiller en Sociología y Antropología de la Universidad de Costa Rica. Desde 2013, coordinador, profesor e investigador de la Cátedra de Sociología de la Escuela de Ciencias Sociales y Humanidades de la UNED. Correo: gcabezas@uned.ac.cr

\footnotetext{
${ }^{1}$ Aprobado por el comité editorial de la Revista Espiga en sesión del 9 de abril de 2021. La sección en que se publica no es arbitrada mediante el proceso de pares.
} 


\section{Introducción}

Franz Hinkelamert hace una referencia elegante del suicidio colectivo, en ella se concibe a la sociedad abrazando con pasión los ideales consumistas (nihilistas) que el modelo económico promete. Alude a la gesta del Cantar de los Nibelungos, donde el tesoro de estos, cubierto por una maldición, no termina en manos de nadie, sino que todos los protagonistas mueren al tratar inútilmente de obtenerlo.

Según Hinkelamert, son los líderes de los pueblos los que quieren este tesoro maldito $\mathrm{y}$, en su promesa de prosperidad y riqueza, para conseguirlo necesitan arrastrar a miles de inocentes, con argucias, a desear para sus jefes esa fortuna, pensando quizá que, en consecuencia, ellos serán prósperos también. No deja de ser sutil la referencia del esfuerzo como sociedad por alcanzar un tesoro que quizá no esté destinado a nosotros; en este banquete de prosperidad que han prometido desde la caída del Muro de Berlín, parece que no se ha sido invitados y hay que contentarse con las migajas que caen de las grandes mesas.

Esta metáfora del profesor Hinkelammert se refiere a un examen crítico de la racionalidad moderna actual, en especial a América Latina, donde la moral y la ética empresarial legitima todos los valores alrededor de las mercancías, el dinero y el mercado, penetrando la vida social. Esto es llamado por el profesor como «metafísica empresarial $»^{2}$, que ha llegado a ser parte de las formas de ser, pensar y sentir del común de las personas, por lo que en diferentes países se escucha con frecuencia «sin dinero no soy nada», «los pobres son pobres porque quieren», «las instituciones públicas son ineficientes» y se maneja esta lógica empresarial de eficiencia y rentabilidad en cualquier organización social, ya sea en iglesias, ONG y hasta en las relaciones interpersonales.

Este relato empresarial se cuela en las decisiones políticas y es así como se asume ser parte de este pleito por migajas, donde ocurren varios fenómenos que enrumban en la senda que recorre Costa Rica y que con la pandemia del COVID-19 se hace más evidente; un recorrido que inicia de manera luminosa en la década de 1980 pero que ha llegado a ser un oscuro sendero que parece haber inmerso a la sociedad no en una crisis, sino en varias -y que distan de la única crisis (la económica) que quieren ver los tecnócratas-: crisis del modelo económico, crisis institucional, crisis migratoria y crisis de representación.

\section{Crisis provocada por el desgaste del modelo económico}

La tozudez del bipartidismo imperante en esa época, que llevó por este sendero desde 1980, hace que sea repetido, una y otra vez, que la crisis económica actual es motivada porque no se aplicó la receta al pie de la letra en aquella década y que se saldrá de ella si se vuelve a comenzar de cero; esta repetición debe de llevar a la reflexión de si verdaderamente se va por el camino correcto.

Un camino que inicia con la necesidad de dar un golpe de timón a otra receta económica, el keynesiano o modelo monetarista, imperante desde la Segunda Guerra Mundial, basado en el consumo mediante el principio de «la demanda efectiva» y donde el desempleo es el resultado de una falta de demanda, por lo que al tener una

\footnotetext{
${ }^{2}$ Franz Josef Hinkelammert, «Las raíces económicas de la idolatría: la metafísica del empresario», en La vida o el capital. Antología esencial. El grito del sujeto vivo y corporal frente a la ley del mercado, ed. por Estela Fernández Nadal (Buenos Aires: CLACSO, 2017), 117-152.
} 
demanda efectiva, es necesario aportar recursos de liquidez a las familias; este dinero funciona no solo como medio de cambio de bienes y servicios, sino que además hace que las familias acumulen valor; este valor, le permite a las personas 1) gastar para consumo y 2) gastar para inversión. Es decir, este modelo se enfoca en la demanda.

Los mercados, para estos keynesianos, producirían la ruina social si se le dejara en su libre albedrío, por lo que el Estado debía regularlos, permitiendo, con una combinación de políticas fiscales (principalmente) y monetarias (después) para equilibrar los ciclos de prosperidad y crisis en los que usualmente el capitalismo suele caer y detener la desigualdad con una serie de instituciones que generaran una distribución de la riqueza.

Por ello, Costa Rica genera una serie de instituciones que permitió un Estado solidario (por ejemplo, la Caja Costarricense de Seguro Social, el Instituto Costarricense de Electricidad, Acueductos y Alcantarillados y el Consejo Nacional de Producción), que, según Acuña ${ }^{3}$

creaban una demanda agregada a favor del Estado por parte de los consumidores (los empleados públicos); es decir, el gasto que realiza el Estado en bienes y servicios a través de las diferentes instituciones que los brindan, le es retribuido al Estado por medio de los consumidores de esos servicios (el público), a través del pago (compra) de esos servicios a un nivel de precios que el consumidor puede pagar.

Esta receta propició el crecimiento económico de muchas naciones con una relativa igualdad, aunque con cierta proporcionalidad, ya que las familias gastan más en bienes de consumo y de inversión, mientras que algunas gastarán menos, manteniendo una proporción media.

Después de 1980, los gobiernos británico y estadounidense se inspiraron en intelectuales que sostenían que el Estado genera una gran desigualdad, ya que los mercados, según ellos, «pueden hacer casi todo mejor» y que las crisis cíclicas siempre han sido explicadas por la intromisión estatal. Mientras que el keynisianismo sostiene que los mecanismos rectores de la economía deben estar en el Estado, este grupo de intelectuales menciona que debe estar en los mercados, retomando elementos clásicos de Adam Smith, fundados en la libertad individual, el egoísmo y la competencia.

Esta doctrina se llamará neoliberalismo y es el manual ideológico que favorece la privatización, la desregularización y el mercado sin ataduras sobre las instituciones públicas y los gobiernos. Ya desde antes, el filósofo Karl Popper era escéptico de que este tipo de liberalización y apertura propiciara el conocimiento y la distribución de la riqueza ${ }^{4}$; a pesar de ello, intelectuales como Friedman y Hayek sostuvieron que la autorregulación de la sociedad por los mercados debe ser celebrada, un mundo organizado casi en su totalidad por las relaciones del mercado es lo que separa a los neoliberales del liberalismo clásico y, esta doctrina, penetraría a los gobiernos de manera sistemática a principios de 1980, con el único fin de revertir las regulaciones de la posguerra, ya que en una sociedad que había superado la Guerra Fría no había

\footnotetext{
${ }^{3}$ Reinhartdt Acuña Torres, «Del Keynesianismo al neoliberalismo», La República, 11 de octubre de 2012, acceso: 30 de agosto de 2021,

https://www.larepublica.net/noticia/del_keynesianismo_al_neoliberalismo

${ }^{4}$ Michael Clune, «Monetarismo vs Keynesianismo. ¿Cómo llegamos a ser neoliberales?», Literal, 10 de julio de 2013, acceso: 30 de agosto de 2021, https://literalmagazine.com/monetarismo-versuskeynesianismo-como-llegamos-a-ser-neoliberales/
} 
que preocuparse, no había razón alguna para que se siguiera con las políticas keynesianas en un mundo donde había triunfado un sistema económico sobre otro.

Este modelo se enfoca principalmente en la libre oferta, generando el equilibrio no en la demanda, sino en los comerciales por la vía de la apertura y el tipo de cambio libre, eliminando los obstáculos de la libre competencia, desregularización de precios y el desmantelamiento de las entidades públicas, que serían concesionadas a las iniciativas privadas. En buena teoría, esta riqueza se desbordaría tanto, como quien llena una botella, que se derramaría al resto de los agentes sociales que, con este derrame, generarían sus propias iniciativas privadas, produciendo empleo y más riqueza.

En ningún momento, dichos pensadores consideraron los elementos de ingeniería fiscal para acaparar hasta la última gota de ese derrame por medio de la elusión, con los paraísos fiscales como los revelados en los Panamá Papers. Según este reporte, Leonel Baruch, exministro de Hacienda, el expresidente Miguel Ángel Rodríguez, empresas como Durman Esquivel o el empresario Samuel Yankelewitz de la Corporación Yanber S.A. (que figura en causas de fraude fiscal y quiebra fraudulenta $)^{5}$, son parte de argucias administrativas que les permitía llevar su riqueza a otros países, domiciliando sus ganancias fuera del derecho costarricense. Por otro lado, no consideraron que la competencia terminaría en grandes oligopolios de empresas multinacionales que devoraban la competencia local por medio de mecanismos como el dumping o las «adquisiciones financieras hostiles» y las incorporarían como sus activos, en el mejor de los casos, o que las dejarían morir hasta ser absorbidas.

Sobre las regulaciones estatales, Huerta menciona que la lógica de la intromisión estatal en el funcionamiento del sistema de precios es la que deteriora la estabilidad y los equilibrios «naturales» del mercado ${ }^{6}$. Se asume en el modelo, que si todos los agentes económicos (empresas) parten de las mismas reglas, poseen la misma información y cuentan con liquidez o acceso a esta por medio de instrumentos financieros para la apropiación de bienes y servicios, no se requiere que alguna instancia pública intervenga en los procesos económicos.

Pero, volviendo al modelo, el cimiento mismo del mercado es el libre comercio y, la libertad de comercio y la apertura comercial, no son conceptos amigables para la agricultura. Es en esta área donde surge la primera víctima de la apertura comercial: el sector primario.

\footnotetext{
5 Juan José Herrera, «Costarricenses mencionados en el caso Panama Papers’ se defienden sobre señalamientos», acceso: 30 de agosto de 2021, https://www.teletica.com/nacional/costarricensesmencionados-en-el-caso-panama-papers-se-defienden-sobre-senalamientos_121031; Álvaro Murillo, «Rodríguez, exsecretario de la OEA, sortea una década de acusaciones», 19 de febrero de 2014, acceso: 30 de agosto de 2021,

https://elpais.com/internacional/2014/02/20/actualidad/1392874473_287936.html; Hulda Miranda, «La historia de una familia que pasó de paraísos fiscales a la quiebra en Costa Rica», Semanario Universidad, 7 de diciembre de 2018, acceso: 30 de agosto de 2021,

https:/semanariouniversidad.com/pais/la-historia-de-una-familia-que-paso-de-paraisos-fiscales-a-laquiebra-en-costa-rica/; Hulda Miranda, «Una tornillería sin ganancias aquí, pero que a la vez repartía dividendos en paraísos fiscales», Semanario Universidad, 6 de diciembre de 2018, acceso: 30 de agosto de 2021, https://semanariouniversidad.com/destacadas/una-tornilleria-sin-ganancias-aqui-peroque-a-la-vez-repartia-dividendos-en-paraisos-fiscales/

${ }^{6}$ María Guadalupe Huerta Moreno, «El neoliberalismo y la conformación del Estado subsidiario», Política y Cultura, . $^{\circ} 24$ (2005): 121-150.
} 
Para el modelo neoliberal, la agricultura es tratada en términos reales y no retóricos, como por ejemplo cuando se habla de la seguridad alimentaria, la protección del ambiente y de las semillas autóctonas. Rojas menciona, en el informe sobre los 10 años del CAFTA en Costa Rica, que la agricultura no pudo competir con EE UU debido al desarrollo del sistema de comercialización, organización de mercados e infraestructura en transportes; igualmente, no pudo con las cuantiosas ayudas que el gobierno federal da a la fecha a sus agricultores ${ }^{7}$. Según OXFAM, antes del tratado, los granjeros estadounidenses recibieron del gobierno federal 649 millones de dólares, 311.4 millones en ayudas directas y 318.3 en pagos contra cíclicos ${ }^{8}$. Este mismo informe menciona que en el 2004 por cada 130 mil dólares invertidos en subsidios y ayudas a granjeros estadounidenses, en Costa Rica se invertían apenas 4 mil. Una vez firmado el tratado, en el informe del 2017 del Estado de la Nación, es decir, a casi 10 años de su implementación, la «nueva economía» llegó a producir cero crecimiento de empleo, mientras que la «vieja economía» producía el $6 \%$ del empleo ${ }^{9}$. Dice el informe que en el estado de la agricultura, 10 años después del Tratado de Libre Comercio (TLC), solo la agroindustria muestra un dinamismo relevante, donde hay una expansión del empleo con baja calificación educativa, pero «este fenómeno ha sido acompañado por un deterioro en la calidad de los puestos de trabajo: mayor informalidad, bajo aseguramiento y menor crecimiento del ingreso» ${ }^{10}$.

Según el Ministerio de Comercio Exterior, actualmente se tienen 16 tratados comerciales vigentes, siendo el más relevante el TLC con EE UU, conocido como CAFTA. Este tratado entró en una polémica, ya que por vía legislativa fue torpedeado por la oposición política hasta que el Poder Ejecutivo lo llevó a cabo vía referéndum; una vez ganado, los legisladores realizaron una agenda de implementación donde, según el sistema costarricense de información jurídica, se realizaron los siguientes cambios jurídicos-institucionales:

- Se aprobó la incorporación a los tratados de Budapest para el registro de patentes de microrganismos, el tratado de derecho de marcas para la propiedad intelectual.

- Se modificó la ley de procedimientos de propiedad intelectual, dos leyes para la apertura de las telecomunicaciones y dos leyes para la apertura de los contratos de seguros. Al Código de Comercio se le modificó el capítulo de inversiones extranjeras (Ley 3284) y se creó una ley para facilitar la propiedad intelectual de semillas y productos vegetales genomizados.

Es decir, Costa Rica asumió dos tratados que giran alrededor de la propiedad intelectual y muy relacionados con la agricultura. Se modificaron seis leyes para facilitar los negocios de telecomunicaciones, seguros y la propiedad intelectual de

\footnotetext{
${ }^{7}$ Warner Rojas, Efectos y consecuencias del Tratado de Libre Comercio (CAFTA) en el sector agrícola de Costa Rica, Repositorio Estado de la Nación 2017, 12-13.

${ }^{8}$ Carlos Galián, El arroz se quemó en el DR-CAFTA, Boston: Oxfam International, 2004, https://oxfamilibrary.openrepository.com/bitstream/handle/10546/114121/bp68-raw-deal-riceDRCAFTA-011104-es.pdf; jsessionid=344D7A6614E6A25DBDBC0CC3705A2890? sequence=2 ${ }^{9}$ PEN-CONARE, Estado de la Nación en desarrollo sostenible, 2017, 134, recuperado de https://estadonacion.or.cr/informes/\# ${ }^{10}$ Ibíd., 123.
} 
especies vegetales genomizadas, llamada con el eufemismo de «semillas certificadas» o semillas genéticamente modificadas ${ }^{11}$.

El TLC-CAFTA es un tratado más y eso está claro. Pero tiene características vistosas que van de lo anecdótico, como escuchar al expresidente Óscar Arias Sánchez prometer que con el tratado los costarricenses tendrían la capacidad adquisitiva de cambiar el automóvil por modelos europeos nuevos; hasta extremos dramáticos en otras partes de América, como la que en el 2013 llevó a cabo una verdadera cacería de productos genomizados, cuya propiedad intelectual pertenece a alguna corporación, donde los gobiernos destruyeron 62 toneladas de arroz en excelente estado, producido por pequeños campesinos por haber incumplido las normas de certificación ${ }^{12}$, siendo estos acuerdos realmente estrictos en las leyes de obtenciones vegetales, pero laxos con los criterios de implementación.

La siguiente víctima está en las relaciones laborales, considerada con el término de «flexibilización laboral», ya que el modelo busca quitar las regulaciones que distorsionan el mercado de trabajo; es decir, en buena teoría se propone que un trabajador, como sujeto «libre», puede no escoger jornadas de trabajo extenuantes y buscar mejores condiciones en otro lugar y vender su fuerza de trabajo a otro oferente que aporte mejores jornadas, como sujeto libre que es.

La realidad es que la necesidad de trabajo olvida que el trabajador en realidad no tiene posibilidad de escoger. Sus características son:

a. Se justifica como forma de mejorar la competitividad de las empresas frente a las protecciones estatales del trabajador.

b. Despidos más baratos, ya que no debe pagarse o se pagarían después las cargas sociales.

c. Subcontratación o tercerización, que es una forma de disfrazar la flexibilización, ya que la entidad no paga a un empleado, sino a una empresa que da un servicio, por lo que no paga las cargas sociales ni los seguros.

d. Aumento o descenso de los salarios según considere la empresa o entidad.

e. Modificación de los horarios o jornadas de trabajo sin previo aviso.

El fenómeno del desempleo surge acá como algo natural al modelo y como una forma de aumentar las ganancias de las empresas que tendrán un stock barato de mano de obra en un contexto más flexible de despidos y subcontrataciones. Más adelante se hará referencia a este fenómeno como parte integral del modelo; por lo pronto, lo importante es señalar que esto, principalmente, genera la desigualdad, ya que el tema laboral antes de la pandemia era grave y con estas medidas se entorpece la posibilidad de mejorar el equilibrio social.

En el siguiente gráfico, con datos del Banco Mundial, se puede apreciar cómo el coeficiente de desigualdad (coeficiente de Gini) en Costa Rica brinca hacia arriba, a partir de 1989, cada vez más, siempre en zonas de alta a moderada desigualdad,

\footnotetext{
${ }^{11}$ Sistema costarricense de información jurídica (CIJ), expediente legislativo \# 16047, Tratado de Libre Comercio República Dominicana-Centroamérica-Estados Unidos (TLC), 2007, http://www.pgrweb.go.cr/SCIJ/Busqueda/Normativa/Normas/nrm_texto_completo.aspx?param1=NR TC\&nValor $1=1 \&$ nValor $2=62270 \&$ nValor3 $=106324 \&$ strTipM $=\overline{T C}$

${ }^{12}$ Mirra Banchón, «Acuerdos comerciales de la UE: ¿un ataque a diez mil años de semillas?», acceso: 30 de agosto de 2021, https://www.dw.com/es/acuerdos-comerciales-de-la-ue-un-ataque-a-diez-mil$\mathrm{a} \% \mathrm{C} 3 \% \mathrm{~B} 1$ os-de-semillas/a-55166927
} 
manteniéndose estacionaria a la fecha en zona de alta desigualdad, lo que en el 2018 hizo entrar al país al top 10 de los países de mayor desigualdad en América Latina ${ }^{13}$. Paradójicamente, Costa Rica es uno de los veinte países más ricos de América, en el lugar 11, según los indicadores del Fondo Monetario Internacional para el $2020^{14}$.

\section{Figura 1}

\section{Coeficiente de Gini en Costa Rica 1989-2019}

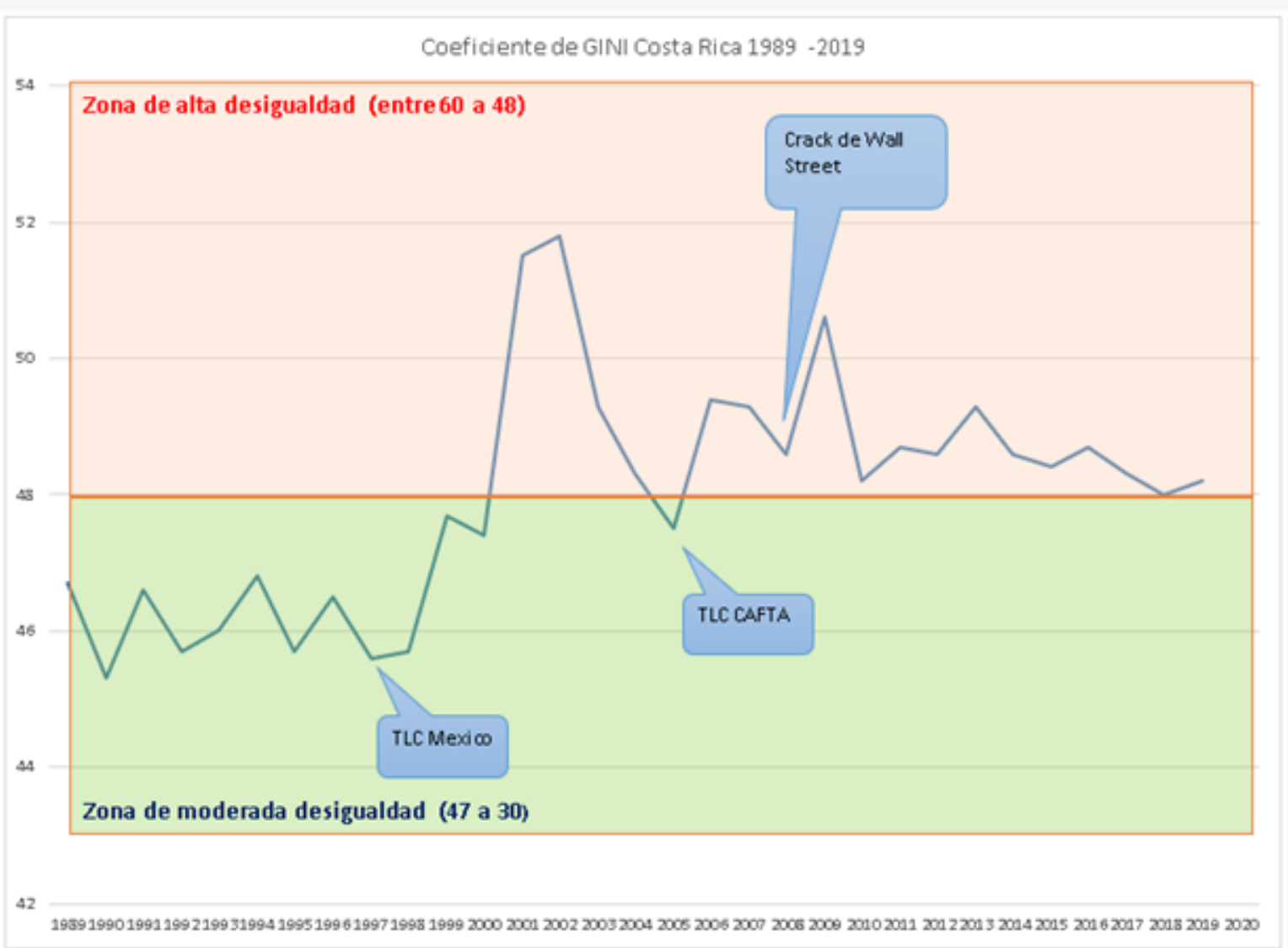

Elaboración propia (2021), con datos del Banco Mundial.

Fuente: https://datos.bancomundial.org/indicator/SI.POV.GINI?locations=CR

Para solventar este fenómeno de la desigualdad, se toman malas decisiones, ya que el modelo menciona que no se deben tocar a las empresas ni tampoco a la inversión extranjera directa, esto porque la riqueza de estas empresas -en teoría- generará servicios asociados que multiplican las posibilidades de empleo; de nuevo el

\footnotetext{
${ }^{13}$ Bernal Monge Pacheco, Costa Rica en el top 10 de la desigualdad, El Financiero, 24 de julio de 2018, acceso: 30 de agosto de 2021, https:/www.elfinancierocr.com/opinion/costa-rica-en-el-top-10de-la-desigualdad/7RGNJN5REBC75EVZAL32AAUNCE/story/

14 «GDP per capita, current prices», Fondo Monetario Internacional (FMI), acceso: 30 de agosto de 2021,

https://www.imf.org/external/datamapper/NGDPDPC@WEO/OEMDC/ADVEC/CMQ/SMQ?year=2 021
} 
concepto del derrame. Lo que se sabe es que esto no es así en todos los casos, el informe Panama Papers demuestra que existen empresas que eluden impuestos mediante paraísos fiscales e ingeniería fiscal; por ello, el Estado reparte lo que no tiene, porque las medidas que se toman para mejorar la igualdad están basadas en endeudamiento, en un sistema de impuestos regresivo, donde se grava al consumo de la clase media y obrera cuando se debería gravar los capitales y quitar las exoneraciones que las empresas tienen, en especial las multinacionales. Por ejemplo, se grava la canasta básica y no se grava en lo mínimo a las empresas ubicadas en zonas francas.

Esto deja al país en una situación delicada, porque una sociedad molesta y desesperada estará dispuesta a asumir cualquier tipo de gobierno, incluyendo aquellos populistas que prometen mejores condiciones; ya esto se ha visto en muchas dictaduras tanto de derecha como de izquierda, donde las personas necesitan una solución en cualquier escenario.

No es casualidad que los principales conflictos mundiales han ocurrido en países al borde de la quiebra que, desesperados, ejercen el voto por cualquiera que les ofrezca solucionar el problema.

Con toda seguridad, se puede decir que a 41 años de que arrancara este modelo, el mundo es más rico y esta riqueza se acapara en unas cuantas manos. Al llegar el escándalo de que 2153 personas en el mundo poseen más riqueza que 4600 millones de personas, la organización OXFAM menciona que

en América Latina y el Caribe el $20 \%$ de la población concentra el $83 \%$ de la riqueza. El número de milmillonarios en la región ha pasado de 27 a 104 desde el 2000. En grave contraste, la pobreza extrema está aumentando. En 2019, 66 millones de personas, es decir, un 10,7 \% de la población, vivía en extrema pobreza, de acuerdo con datos de la Comisión Económica para América Latina y el Caribe (CEPAL). ${ }^{15}$

No es casualidad que lejos de generar un mayor bienestar, el cambio de modelo generó que las mujeres y las niñas realizaran trabajos no remunerados de un valor de 10,8 billones de dólares anuales, al trabajar 12500 millones de horas diariamente sin recibir un solo centavo por ese trabajo realizado ${ }^{16}$. Esto demuestra que el crecimiento económico no es igual a desarrollo.

\section{Crisis institucional}

Se habla de derrames y migajas, siempre de lo que se cae de la mesa principal. Se colecciona migajas y se atesoran porque son propias y, como propiedad, se ha criminalizado toda forma de acción que termine por apropiarse por lo que le pertenece a cada quien.

Ciertamente el desmantelamiento de la institucionalidad del Estado ha generado que el Estado mismo pierda credibilidad al no satisfacer las necesidades de los miembros de la sociedad. Huerta menciona que esto generó un deterioro progresivo de los vínculos políticos y sociales que existían en el ejercicio del poder, trasformando «la gestión gubernamental por un lado y la atención de las demandas sociales por

\footnotetext{
${ }^{15}$ OXFAM International, «Los milmillonarios del mundo poseen más riqueza que 4600 millones de personas», acceso: 30 de agosto de 2021, https://www.oxfam.org/es/notas-prensa/los-milmillonariosdel-mundo-poseen-mas-riqueza-que-4600-millones-de-personas

${ }^{16}$ OXFAM International, «Los milmillonarios del...
} 
otro» ${ }^{17}$. Se ha repetido tantas veces que el Estado no es eficiente en llevar a cabo los servicios que se ven como el estrangulamiento presupuestario, ha llevado a las instituciones a concesionar servicios y se ve normal, incluso se ha asumido que verdaderamente el Estado no puede realizar dichas actividades. El filósofo Noam Chomsky indica que: «(...) esta es la técnica estándar de la privatización; cortar el presupuesto para asegurarse que las cosas no funcionen. La gente se molesta y se usa como excusa pasarlo a manos del capital privado en aras de la eficiencia» ${ }^{18}$.

Como ejemplo se pueden tomar algunas empresas como la española Autopistas del Sol (hoy Globalvía) en la Ruta 27 San José-Caldera, la cual, el expresidente Arias Sánchez denominó «una autopista del primer mundo». La supervisora GetinsaGabinete, en su informe de octubre de 2020, hizo 68 señalamientos por el mal estado de la carretera, sin decir el incumplimiento del contrato previo de la concesionaria española para realizar una ampliación que a la fecha no ha cumplido ${ }^{19}$. Otro ejemplo es la terminal de contenedores de Moín, APM Terminals, que elevó los precios de carga y descarga, al punto de que el empresario, político y expresidente legislativo, Antonio Álvarez Desanti, aseguró que el monopolio de APM fue un error y que «extraña» a JAPDEVA; esto sin contar las enormes colas de camioneros que fuera del muelle esperan días para llegar a descargar o cargar mercadería ${ }^{20}$. Otro ejemplo es la mala administración de los Equipos Básicos de Atención en Salud (EBAIS), por intermedio de las cooperativas administradoras, donde el servicio fue desmejorando al punto de que en muchos EBAIS envían al paciente a hospitales de la CCSS para exámenes de laboratorio, cuando deberían ser los centros de salud primaria los que deben hacerlo ${ }^{21}$.

La inclinación del neoliberalismo por contar con un Estado mínimo ha generado, según Alix ${ }^{22}$, un choque entre la democracia y el capitalismo, ya que la prioridad «que se establece entre el funcionamiento del libre mercado y la preservación de los derechos, a favor del primero, o entre el imperativo de la productividad y el cuidado de los derechos, también en beneficio del primero»; siendo más relevante el mercado que, en términos prácticos, se refiere a la inversión extranjera directa, eufemismo para empresas transnacionales con inversiones en el país. La interferencia estatal en las actividades de los individuos distorsiona el mercado y altera las relaciones

\footnotetext{
${ }^{17}$ Huerta, «El neoliberalismo y...

${ }^{18}$ Chomsky, Noam, Ilusiones necesarias. Control del pensamiento en las sociedades democráticas (Madrid: Ed. Libertarias/Prodhufi, 1992).

${ }^{19}$ Javier Córdoba, «Supervisora hace 68 recomendaciones de multa a Globalvía por mal estado de la Ruta 27», Semanario Universidad, 27 de enero de 2021, acceso: 30 de agosto de 2021,

https:/semanariouniversidad.com/pais/supervisora-hace-68-recomendaciones-de-multa-a-globalviapor-mal-estado-de-la-ruta-27/

${ }^{20}$ María Núñez Chacón, «APM Terminals se desbordó el fin de semana y filas de furgones colapsaron Ruta 32», Semanario Universidad, 22 de marzo de 2021, 30 de agosto de 202, https://semanariouniversidad.com/pais/apm-terminals-se-desbordo-el-fin-de-semana-y-filas-defurgones-colapsaron-ruta-32/

${ }^{21}$ Óscar Ugarte Jiménez, «Sectores sociales y empresariales se enfrentan por manejo privado de Ebais», Semanario Universidad, 14 de noviembre de 2020, 30 de agosto de 2021, $\mathrm{https}$ ://semanariouniversidad.com/pais/sectores-sociales-y-empresariales-se-enfrentan-por-manejoprivado-de-ebais/

${ }^{22}$ Luis Lloredo Alix, La crisis y desmantelamiento del Estado de derecho: de derechos a privilegios, Revista Papeles de relaciones ecosociales y cambio global, Núm. 124 2013/14, 37-51, https://www.researchgate.net/profile/Luis-Lloredo-

Alix/publication/269634423_La_crisis_y_el_desmantelamiento_del_Estado_de_Derecho_de_derecho s_a_privilegios/links/5490ab010cf214269f $2 \overline{7} \mathrm{~d} 367 /$ La-crisis-y-el-desmantelamiento-del-Estado-deDerecho-de-derechos-a-privilegios.pdf?origin=publication_detail
} 
sociales, de allí la importancia de disminuir los costos fiscales que un Estado conlleva, con el propósito de darle a los individuos la oportunidad de generar sus propias empresas o emprendimientos.

Evidencia de esta priorización es cómo en los diferentes países de Latinoamérica se favorece el pago de la deuda sobre cualquier elemento social o satisfacción de derechos, la propiedad y el acaparamiento de la riqueza es esencial para que se dé el tal ansiado derrame.

Por ello, no es casualidad que se penalice el uso o la apropiación de la propiedad de otro y lo que atente contra las libertades individuales, porque al final de todo, en la sociedad actual, basada en la acumulación de bienes individuales, es necesario proteger lo privado a como dé lugar.

Estas salvaguardas al actual estilo de vida han llevado por varios caminos. Primero, a guerras por defender las creencias y posesiones en sitios tan lejanos como Afganistán o Iraq; luego, antaño hubo alegría en las primaveras árabes de Egipto, Túnez y Libia, porque quieran vivir como Occidente, o al menos así se ve. Que tengan las migajas que se tiene en esta región: pantalones de mezclilla, cigarrillos variados, teléfonos inteligentes, televisión digital, muebles nórdicos, tapetes y toda una gama de gadgets.

Este estilo de vida tiene una consecuencia: si se tiene lo que ellos quieren, existe el peligro de que quieran venir por ello; esto lleva al segundo camino: y es que si bien se necesita a los inmigrantes para que sus manos realicen tareas que las manos propias no quieren realizar (recolectar la fruta, cuidar el vecindario en la garita de la esquina, realizar labores domésticas), se imagina que se ve en estos inmigrantes los ojos rojos de ansias por quitar lo propio, esas migajas que tanto se han atesorado, lo que lleva a la siguiente crisis.

\section{Crisis migratoria}

Costa Rica ha desarrollado una serie de características económicas y políticas que le han dado atractivo como país de inmigrantes. Estos procesos migratorios tienen que ver con diferentes razones, entre las cuales están las de orden financiero, ya que muchos de los inmigrantes son refugiados económicos ${ }^{23}$.

No es de sorprender que, en un clima de crecimiento de los crímenes violentos, la inmigración sea el chivo expiatorio de los problemas nacionales. Los medios de comunicación, junto con otros agentes creadores de opinión pública, incitan al dañino y potencialmente peligroso paralelismo entre inmigración y delincuencia.

Tradicionalmente, no solo en Costa Rica, de forma deliberada, se ha vinculado la inseguridad y la delincuencia al fenómeno migratorio, al punto de mencionar que se está bajo una «crisis migratoria». Ciertamente, se trata de una preocupación de importante validez para la ciudadanía y se factoriza la imposibilidad de la población inmigrante (tanto regular como irregular) de influir de forma directa por medio del sufragio en los diferentes estamentos del poder público. Es fácil entender, por lo menos, una cierta tendencia demagógica.

\footnotetext{
${ }^{23}$ María Núñez Chacón, «Inmigrantes llegan a Costa Rica impulsados por la miseria», Semanario Universidad, 6 de noviembre de 2018, 30 de agosto de 2021, https://semanariouniversidad.com/universitarias/inmigrantes-llegan-a-costa-rica-impulsados-por-lamiseria/
} 
Esta falta de poder político se debe agregar a una visión distorsionada que tienen los individuos por el desconocimiento cultural del país de origen de los inmigrantes, que dificulta su integración armoniosa; ya que este desconocimiento es en ambos sentidos, o sea, que tanto los de aquí como los de allá crean una barrera al deseado objetivo de la integración, amén de otras barreras de importancia (diferencias lingüísticas, carencia de estatus legal definido, etc.).

Los conflictos derivados de este desconocimiento cultural recíproco tienden a escenificarse, fundamentalmente, a propósito de la convivencia en proximidad entre culturas con rivalidades históricas. Sin embargo, reconocer la yuxtaposición cultural como hecho, dentro de una sociedad como si fuera multiétnica, religiosamente diversa y pluricultural, es poco tolerado, por lo que no es extraño observar manifestaciones de intolerancia racial y étnica que los responsabiliza de los problemas como la delincuencia, la escasez de trabajo y la alteración de la identidad nacional ¿Se piensa en colombianos cuando se habla de secuestros? ¿Si dicen tráfico de marihuana se piensa en jamaiquinos o dominicanos? ¿Y si dicen violencia doméstica, robos o estafas se piensa en nicaragüenses? Todo esto sin importar si se menciona la nacionalidad de los perpetradores.

Sin lugar a dudas, la visión de la población autóctona acerca de la llegada de personas inmigrantes tiene detrás un inquietante miedo a la pérdida de oportunidades laborales, pérdida de valores autóctonos y, por supuesto, pérdida de bienes (migajas). No se toma en cuenta las necesidades del mercado laboral en algunos sectores (agropecuario, especialmente la piña, la corta de caña y la cogida de café), sobre todo en la mano de obra necesaria para cubrir estos espacios que los costarricenses se niegan a satisfacer (servicios domésticos, construcción y policía privada de barrios, por ejemplo). La falta de memoria histórica es evidente en el contenido de los discursos sociales que se utilizan, la pandemia descubre cómo en San Carlos es común el trabajo cuasi esclavo en las piñeras, con poco o nada de seguridad social ni de las dificultades que tienen los pueblos transfronterizos Ngäbe Buglé, para asegurarse algo de la riqueza que genera la cosecha cafetalera.

Resumiendo, se puede mencionar que, en el bicentenario de su independencia, Costa Rica enfrenta varias crisis y mantiene un modelo económico desgastado y que ha demostrado ser desastroso para la sociedad misma y los derechos de su ciudadanía, una institucionalidad de un Estado que ha cambiado su forma de relacionarse con los miembros de la sociedad, una crisis migratoria donde la miseria azuza los pies de las personas que buscan una mejor vida, generada por las mismas circunstancias que el modelo ha tenido en sus países de origen. Pero aún queda una más, es la crisis de representación.

\section{Crisis de representación}

En el informe de los resultados de la encuesta de opinión pública, realizada por el Centro de Investigación y Estudios Políticos (CIEP) de la Universidad de Costa Rica y el Programa Estado de la Nación (PEN) en abril del 2020, en uno de los cuadros se menciona la identificación de los principales problemas del país desde el 2013, en él, el desempleo es repetido seis veces de las ocho que se menciona ${ }^{24}$; además, se nombran otros como el costo de la vida y la inseguridad. No es sino hasta el 2018, año electoral, que se menciona uno más: la situación fiscal.

\footnotetext{
${ }^{24}$ Ronald Alfaro Redondo, «Elecciones 2018 en Costa Rica: retrato de una democracia amenazada», CONARE-PEN, 2020, https://ciep.ucr.ac.cr/libro-democracia-amenazada/
} 
Todos tienen un común denominador, la relación que el Estado tiene con los individuos, como bien se mencionaba líneas arriba. No es para menos, ya que el desempleo es «creado» por el modelo mismo. En el capítulo 23 del tomo primero del texto El Capital, titulado «La ley general de la acumulación capitalista», Marx afirmó que: «(...) la condena de una parte de la clase obrera a la inactividad impuesta por el exceso de trabajo de la otra parte se convierte en un medio de enriquecimiento de los capitalistas individuales»; entonces, el desempleo es una forma más de enriquecimiento de las empresas y no un problema individual ni tampoco un problema de gestión de un Estado, ya que poder garantizar de forma constante que una parte de la población se mantenga desempleada, permitirá que la amenaza del desempleo sea la forma en que los individuos acepten condiciones laborales precarizadas y se legitime esto como «esfuerzo», «lucha», etc.; mientras que las condiciones laborales óptimas, como para individuos vagos, perezosos e inútiles, estigmatizando a la persona desempleada. Entre tanto, se aumentan las jornadas de trabajo, se automatizan o tercerizan las funciones y se súper especializan los puestos de trabajo, por lo que una buena parte de la población queda excluida de las fuentes de empleo.

Por tanto, en un país donde impera la ley de la oferta y la demanda, donde el mercado es suficiente para regular las relaciones sociales, el desempleo debería desacelerar el crecimiento; sin embargo, y de manera paradójica, ocurre todo lo contrario. Es decir, para el neoliberalismo, el motor del crecimiento no debería ser el Estado y este no debería tener control de la moneda, dejando el tipo de cambio a la libre (flexibilizado, como suelen decir); por tanto, el sector privado puede tener las condiciones de crecimiento enfocadas en el crecimiento hacia afuera (exportaciones). En buena teoría, la austeridad fiscal y la marginación de los Estados en la economía deberían generar crecimiento; pero lo cierto es que el crecimiento se da porque la austeridad y la disciplina fiscal solo favorecen al sector financiero; por esto, el desempleo y la falta de consumo deteriora a toda la esfera de la productividad, aumentando el costo de la vida y, así, el Estado no tiene la capacidad de hacer un manejo soberano de su propia economía.

De igual forma, los sociólogos García y Wacquant vinculan de forma directa que el binomio seguridad-riesgo está, de manera sistemática, asociado al neoliberalismo, no solo por la precariedad social que el modelo genera, sino, también, porque imprime en las personas una idea de competitividad e incertidumbre que rompe los lazos comunitarios, trasformando las ideas igualdad-fraternidad en libertadseguridad y entendiendo a la libertad como libertad de empresa y no libertad de pensamiento ${ }^{25}$. Es decir, la libertad del mercado y la seguridad para los mercados, generando más policía y castigo, sin sorprender, a un momento donde electoralmente se ve muy bien un discurso de la vuelta a la disciplina.

Paradójicamente, el Estado no puede hacerse cargo de esta seguridad, no importa cuánto aumenten las penas o cuántas leyes nuevas surjan, simplemente porque no existen los recursos debido al estrangulamiento financiero que aparece de la austeridad y disciplina fiscal. Este debilitamiento ya había generado que modelos de criminalidad igualmente especializados en el mercado externo se hiciera cada vez más fuerte, como bien señalan Guerrero y Domínguez sobre el debilitamiento del Estado por las políticas neoliberales en El Salvador, Guatemala y Honduras, estas,

\footnotetext{
${ }^{25}$ Beatriz García, García, Eva, Montero, Virginia, Parajuá, Daniel, Wacquant, Loic, Stavrides, Stavros y Bonelli, Laurent, Enclaves de riesgo. Gobierno neoliberal, desigualdad y control social, Prevención 12 (270), 14, 2015.
} 
si bien generaron un fuerte crecimiento económico, produjeron a su vez un proceso de desindustrialización con repercusiones en las variables empleo y subempleo, ingresos y salarios, pobreza y desigualdad, esto es, el crecimiento económico no brindó seguridad a la ciudadanía y, contradictoriamente, dejó un saldo negativo a la sociedad en general al dispararse las tasas de homicidios y delitos de oportunidad que son comunes en los países del Triángulo Norte $^{26}$, producido tanto por el tránsito del narcotráfico, como el tráfico de seres humanos y el fortalecimiento de las pandillas como pequeños Estados paralelos.

Se tiene entonces este escenario donde la incapacidad del Estado para resolver estos problemas sociales con dos elementos que se favorecen de esta incapacidad: 1) el desinterés de redistribuir la riqueza por parte de los gobiernos de turno y de los mercados que ayudarían a resolver esos problemas sociales, y 2) las entidades estatales favorecen una corrupción institucionalizada mediante una laberíntica burocracia y la penetración del narcotráfico entre los grupos de seguridad, han fracturado las estructuras políticos-sociales, ocasionando una gran desconfianza en los partidos políticos, lo que genera una paradoja en la democracia. Esta paradoja consiste en que la población, al tratar de recuperar el Estado anterior, vota por aquellos que le prometen tal cosa y lleva al poder a grupos populistas que hacen exactamente lo contrario a lo que significan las democracias.

Díaz menciona que el populismo es una promesa redentora de las formas de ser, pensar y sentir de una sociedad, pero al mismo tiempo entroniza a un líder que diluye las formas de participación que caracteriza a una democracia, así se generan estrategias que deslegitiman a todo aquel que haga un análisis crítico de acusaciones o que se oponga abierta o veladamente al poder, generando «un enemigo» ${ }^{27}$.

Esta es la principal característica de la polarización social que se ve no solo en América Latina, sino también en naciones desarrolladas, que llevan al poder a figuras con extrema rigidez, siendo incapaces de reformarse y adaptarse a nuevas condiciones sociales; por ello, suele verse en estos movimientos, un inflacionismo punitivo como respuesta, así como discursos en redes sociales basados en noticias falsas.

Alfaro retrata esa polarización, que influyó en las elecciones de 2018, tanto de primera como de segunda ronda. Indica que estas elecciones fueron un parte aguas devenido de esta crisis de representación, al punto de que se «transformaron las identidades sociales y políticas en la población en temas poco relacionados con las luchas partidarias tradicionales $\rangle^{28}$.

Este mismo autor menciona que «el debilitamiento de las identidades políticas y partidarias tornan más vulnerables a los votantes a alternativas populistas, de distinto signo ideológico, que ofrecen soluciones mesiánicas al malestar con la política» ${ }^{29}$. Este declive, quisiera insistir, no es consecuencia del descrédito y la corrupción, sino

\footnotetext{
${ }^{26}$ Guerrero, Cristina y Domínguez, Miguel, «Violencia: criminalidad e inseguridad en el triángulo del norte de Centroamérica, aristas del modelo Neoliberal», Revista SAPIENTIAE: Revista de Ciencias Sociais, Humanas e Engenharias, vol. 5, núm. 1, 157-181, 2019, https://www.redalyc.org/journal/5727/572761149008/movil/

${ }^{27}$ José Andrés Díaz Gonzáles, reseña del libro: El populismo en escena. ¿Por qué emerge en unos países y en otros no?, Revista Rupturas 8 (1), Ene-Jun, 2018, https://www.scielo.sa.cr/pdf/rup/v8n1/2215-2989-rup-8-01-235.pdf

28 Alfaro, «Elecciones 2018 en Costa Rica...

29 Ibíd.
} 
que es fruto directo de las medidas del debilitamiento institucional que ha venido desmantelando aquellas instituciones que aportaban paz social.

\section{A modo de conclusión}

Como país, se ha respondido a los cambios a nivel local e internacional. Costa Rica es una nación construida con presiones, ideas, demandas y tropiezos; tiene virtudes como democracia, ha avanzado en algunos elementos y retrocedido en otros; se ha elegido ser una nación solidaria, pero en ocasiones se comporta como si no quisiera serlo. Es una nación que invierte enormemente en educación pero surgen voces que tratan de sustituir la educación con el emprendimiento como forma de acenso social; se ha introducido esa lógica metafísica empresarial en las interacciones sociales, incluso en las más básicas. Es acá donde se debe ver qué se tiene para saber qué hacer.

a. Crisis social generada por una globalización económica, que produce grandes bolsas de exclusión social, el abandono del Sur y los cambios radicales de los países del Este que provocan un incremento de presión migratoria, produciendo notorias bolsas de marginación. Este punto fue abordado en la sección precedente. En Centroamérica, esta globalización tiene como antesala los Programas de Ajuste Estructural y las agresivas reformas financieras de la década de 1980 y, más recientemente, los planes de rescate para evitar crisis nacionales.

b. Crisis del Estado de bienestar, causada por la universalización de los servicios de salud, energía, carga impositiva solidaria, etc., todo previo a la década de 1980, que conlleva recortes sociales en momentos donde los más desfavorecidos y marginados reclaman atención solidaria difícil de obtener de otra manera y mucho menos del mercado en sociedades basadas en la acumulación de capital. Se debe insistir en los planes de rescate o escudo de los Estados, contra la crisis producida por los fondos inmobiliarios en EE UU, basados en la perversa lógica de que es imposible que los pobres eliminen la crisis, por lo que se debe ayudar a los ricos para que sus empresas que producen empleo no quiebren y, por supuesto, no dejen de consumir.

c. Por último, una crisis de proyectos y representación que se manifiesta por la ausencia de perspectivas claras ante el desmantelamiento de las doctrinas ideológicas redentoristas que han dominado el pensamiento hasta ahora. Han quedado algunas alternativas ideológicas y modelos económicos que, en la praxis, distan mucho de ser lo que son: se dice prosperidad para todos sin redistribución de la riqueza; se dice modernizar el Estado como un eufemismo de disminuir el tamaño del Estado, sin que ninguno haya demostrado en el tiempo cumplir sus promesas.

Si a estos cambios se añade el complicado y lento proceso de unidad nacional frente al actual modelo económico, el renacimiento de nacionalismos agresivos y excluyentes, el desarrollo del individualismo posesivo inherente a la lógica del mercado sin límite y la cultura del consumo a la ultranza triunfalista, junto a cierto cansancio democrático y la desmovilización de los demócratas profundos, se encuentra un panorama bastante preocupante, donde el discurso de la intolerancia se mueve en su hábitat, busca -y siempre encuentra- uno o varios grupos minoritarios a los que discrimina, segrega y margina, en consecuencia, atribuye a los grupos estigmatizados una diferencia que les hace inferiores o peligrosos.

Probablemente es la Revolución Francesa la culpable de que se crea en la libertad, igualdad y fraternidad en las sociedades basadas en la acumulación de capital; sin 
embargo, es difícil encontrar igualdad cuando en una sociedad que, como la europea, se quiera ejercer la libertad religiosa, impidiendo que las mujeres utilicen el velo islámico en aras de la seguridad, ni qué decir, de que se quiera la igualdad de la educación de los pieds-noirs; esto no es distinto en absoluto de lo que sucede en Costa Rica: la educación pública en sitios como La Carpio, donde no se imparte ninguna materia especial (música, artes industriales, artes plásticas o física) y la jornada es menor que la normal, no es la misma que la misma educación pública de una escuela en un suburbio infinitamente distinto.

Sin embargo, basado es ese mito posterior a la toma de la Bastilla, se cree, a pie juntillas, en los relatos de los igualiticos, en la sociedad pacífica con una clase media mayoritaria. Relatos que chocan contra la realidad de una sociedad en ebullición, racista y xenófoba y con una clase media en franca decadencia, tal como el Programa Estado de la Nación lo menciona en su informe como «la mayor parte de la desigualdad registrada en estos veinte años se origina en las diferencias dentro de las clases sociales, donde la heterogeneidad es grande, sobre todo en la clase alta y en la de medianos empresarios y expertos $\rangle^{30}$. Este mismo informe plantea que, según el Instituto Nacional de Estadística y Censo (INEC), las clases pobres son el $43 \%$ de la población costarricense y estos tienen apenas el $15.8 \%$ de la riqueza del país, luego, el $40.5 \%$ son de estratos medios y un $14.7 \%$ de clases altas. Entonces ¿Cómo no creer que este grupo tan importante de clases pobres va a dejar de ser fraternal?

El ejemplo de la austeridad en países desarrollados después del crack del 2008 solo erosionó la capacidad de los Estados para dar respuesta a los problemas sociales e implicaron el desmantelamiento de las instituciones de salud que, en el caso de Grecia e Italia, produjo la destrucción gradual del sistema de salud, que al estallar la pandemia trajo efectos devastadores.

Igual la destrucción de las fuentes de empleo genera una enorme carga estatal, generando un círculo vicioso, ya que las empresas han ganado aquellos elementos necesarios para el desdoblamiento de los derechos laborales que tanto costó construir desde la década de 1930 .

Pareciera ser que hoy, frente al bicentenario, hay que preguntarse si se debiera seguir por esa ruta de extracción de los recursos naturales a precios de intercambio deteriorados, con la amenaza del populismo en cada elección. ¿Quién los puede culpar? Ya lo decía Manuel Mora Valverde a José Figueres Ferrer en 1945: «Las grandes masas indígenas y mestizas de América Latina solo conocen la miseria y la explotación. Viven en chozas inmundas, se alimentan de frijoles y plátanos sin manteca, mueren sin auxilios médicos y trabajan jornadas agotadoras todos los días ${ }^{31}$. Se tiene zonas costeras y montañosas abandonadas a su suerte con municipalidades que piensan solo en términos electorales a una suerte de Estado fallido que cuesta reconocer.

Los TLC no trajeron prosperidad, pero, siendo francos, tampoco trajeron una debacle. El reto hoy es la desigualdad, fortaleciendo el impacto de la política social que es la clave para garantizar el acceso a servicios de salud y una educación de calidad, a la protección del ambiente, del patrimonio alimentario, universalizando la educación secundaria y el crecimiento inclusivo de los ingresos. Quizá así no se termine en una situación de suicidio colectivo. En la gesta de los Nibelungos, el

\footnotetext{
${ }^{30}$ Programa Estado de la Nación. Estado de la Nación 2020. San José: CONARE-PEN, 2020.

${ }^{31}$ Mora Valverde, Manuel. Discursos, 1934-1979 (San José: Editorial Presbere, 1980).
} 
héroe de la historia, Sigfrido, gana el anillo, pero muere asesinado por traición, por lo que el anillo termina de nuevo en el río Rin perdiéndose para siempre y, al hacerlo, todos los dioses son destruidos.

El camino que sigue el país aporta un gran crecimiento económico, pero repartido de manera tan desigual que esto puede volverse en contra del propio sistema, destruyendo a los dioses mismos de la prosperidad. En el cuento de Moby Dick, el capitán Acab está dispuesto a morir con toda su tripulación para satisfacer su sed de venganza, igual ocurre con los gobiernos que no reconocen que el sistema no funcionó, así que ellos, al igual que el capitán, buscan una ballena blanca y la obsesión de la muerte como destino, cuando no debería ser nuestra meta como nación solo para demostrar que el sistema pudo funcionar.

Todavía estamos a tiempo para salir de esta búsqueda sin sentido de la prosperidad con este modelo en la que nos han metido.

\section{Formato de citación según APA}

Cabezas-Barrientos, G. (2021). El ocaso de los dioses de la prosperidad después del TLC y en vísperas del bicentenario. Neoliberalismo, desigualdad y el ascenso de los populismos en Costa Rica. Revista Espiga, 20 (42), 121-139.

Formato de citación según Chicago-Deusto

Cabezas-Barrientos, Gustavo. «El ocaso de los dioses de la prosperidad después del TLC y en vísperas del bicentenario. Neoliberalismo, desigualdad y el ascenso de los populismos en Costa Rica». Revista Espiga 20, n. ${ }^{\circ} 42$ (setiembre, 2021): 121-139. 


\section{Referencias}

Asamblea Legislativa de Costa Rica. Expediente legislativo \# 16047, Tratado de Libre Comercio República Dominicana-Centroamérica-Estados Unidos (TLC), 2007.

http://www.pgrweb.go.cr/SCIJ/Busqueda/Normativa/Normas/nrm_texto_co mpleto.aspx?param $1=$ NRTC\&nValor $1=1 \& n$ Valor $2=62270 \& n$ Valor $3=1 \overline{0} 632$ $4 \&$ strTipM=TC

Acuña Torres, Reinhardt. «Del Keynesianismo al neoliberalismo». La Republica. 11 de octubre de 2012. Acceso: 30 de agosto de 2021.

https://www.larepublica.net/noticia/del_keynesianismo_al_neoliberalismo

Alfaro Redondo, Ronald. «Elecciones 2018 en Costa Rica: retrato de una democracia amenazada». CONARE-PEN, 2020. https://ciep.ucr.ac.cr/librodemocracia-amenazada/

Banchón, Mirra. «Acuerdos comerciales de la UE: ¿un ataque a diez mil años de semillas?» Acceso: 30 de agosto de 2021. https://www.dw.com/es/acuerdoscomerciales-de-la-ue-un-ataque-a-diez-mil-a $\% \mathrm{C} 3 \% \mathrm{~B} 1$ os-de-semillas/a55166927

Chomsky, Noam. Ilusiones necesarias. Control del pensamiento en las sociedades democráticas. Madrid: Ed. Libertarias/Prodhufi, 1992.

Guerrero, Cristina y Domínguez, Miguel. «Violencia: criminalidad e inseguridad en el triángulo del norte de Centroamérica, aristas del modelo Neoliberal». Revista SAPIENTIAE: Revista de Ciencias Sociais, Humanas e Engenharias, Vol. 5, Núm. 1, 157-181, 2019.

https://www.redalyc.org/journal/5727/572761149008/movil/

Clune, Michael. «Monetarismo vs Keynesianismo. ¿Cómo llegamos a ser neoliberales?» Literal. 10 de julio de 2013. Acceso: 30 de agosto de 2021. https://literalmagazine.com/monetarismo-versus-keynesianismo-comollegamos-a-ser-neoliberales/

Córdoba, Javier. «Supervisora hace 68 recomendaciones de multa a Globalvía por mal estado de la Ruta 27». Semanario Universidad. 27 de enero de 2021. Acceso: 30 de agosto de 2021. https://semanariouniversidad.com/pais/supervisora-hace-68recomendaciones-de-multa-a-globalvia-por-mal-estado-de-la-ruta-27/

Díaz Gonzáles, José Andrés. Reseña del libro: El populismo en escena. ¿Por qué emerge en unos países y en otros no? Revista Rupturas 8 (1), Ene-Jun, 2018. https://www.scielo.sa.cr/pdf/rup/v8n1/2215-2989-rup-8-01-235.pdf

Fondo Monetario Internacional (FMI). «GDP per capita, current prices». Acceso: 30 de agosto de 2021. https://www.imf.org/external/datamapper/NGDPDPC@WEO/OEMDC/AD $\mathrm{VEC} / \mathrm{CMQ} / \mathrm{SMQ}$ ?year=2021 
García, Beatriz, García, Eva, Montero, Virginia, Parajuá, Daniel, Wacquant, Loic, Stavrides, Stavros y Bonelli, Laurent. Enclaves de riesgo. Gobierno neoliberal, desigualdad y control social. Prevención, 12 (270), 14, 2015.

Rojas, Warner. Efectos y consecuencias del Tratado de Libre Comercio (CAFTA) en el sector agrícola de Costa Rica. Repositorio Estado de la Nación 2017, 12-13.

Hinkelammert, Franz Josef. «Las raíces económicas de la idolatría: la metafísica del empresario». En La vida o el capital. Antología esencial. El grito del sujeto vivo y corporal frente a la ley del mercado, editado por Estela Fernández Nadal, 117-152. Buenos Aires: CLACSO, 2017.

Huerta Moreno, María Guadalupe. «El neoliberalismo y la conformación del Estado subsidiario». Política y cultura, n. ${ }^{\circ} 24$ (2005): 121-150. http://www.scielo.org.mx/scielo.php?script=sci_arttext\&pid=S0188$77422005000200006 \& \operatorname{lng}=\mathrm{es} \&$ tlng=es

Herrera, Juan José. «Costarricenses mencionados en el caso 'Panama Papers' se defienden sobre señalamientos». Acceso: 30 de agosto de 2021. https:/www.teletica.com/nacional/costarricenses-mencionados-en-el-casopanama-papers-se-defienden-sobre-senalamientos_121031

Miranda, Hulda. «La historia de una familia que pasó de paraísos fiscales a la quiebra en Costa Rica». Semanario Universidad. 7 de diciembre de 2018. Acceso: 30 de agosto de 2021. https://semanariouniversidad.com/pais/lahistoria-de-una-familia-que-paso-de-paraisos-fiscales-a-la-quiebra-en-costarical

Miranda, Hulda. «Una tornillería sin ganancias aquí, pero que a la vez repartía dividendos en paraísos fiscales». Semanario Universidad. 6 de diciembre de 2018. Acceso: 30 de agosto de 2021. https://semanariouniversidad.com/destacadas/una-tornilleria-sin-gananciasaqui-pero-que-a-la-vez-repartia-dividendos-en-paraisos-fiscales/

Mora Valverde, Manuel. Discursos, 1934-1979. San José: Editorial Presbere, 1980.

Monge Pacheco, Bernal. Costa Rica en el top 10 de la desigualdad. El Financiero, 24 de julio de 2018. https://www.elfinancierocr.com/opinion/costa-rica-enel-top-10-de-la-desigualdad/7RGNJN5REBC75EVZAL32AAUNCE/story/

Murillo, Álvaro. «Rodríguez, exsecretario de la OEA, sortea una década de acusaciones». El País. 19 de febrero de 2014. Acceso: 30 de agosto de 2021. https://elpais.com/internacional/2014/02/20/actualidad/1392874473_287936. html

Núñez Chacón, María. «APM Terminals se desbordó el fin de semana y filas de furgones colapsaron Ruta 32». Semanario Universidad. 22 de marzo de 2021. Acceso: 30 de agosto de 2021. https://semanariouniversidad.com/pais/apm-terminals-se-desbordo-el-fin-desemana-y-filas-de-furgones-colapsaron-ruta-32/ 
Núñez Chacón, María. «Inmigrantes llegan a Costa Rica impulsados por la miseria». Semanario Universidad. 6 de noviembre de 2018. Acceso: 30 de agosto de 2021.

https://semanariouniversidad.com/universitarias/inmigrantes-llegan-a-costarica-impulsados-por-la-miseria/

Galián, Carlos. El arroz se quemó en el DR-CAFTA. Boston: Oxfam International, 2004.

https:/oxfamilibrary.openrepository.com/bitstream/handle/10546/114121/bp 68-raw-deal-rice-DRCAFTA-011104-

es.pdf;jsessionid $=344 \mathrm{D} 7 \mathrm{~A} 6614 \mathrm{E} 6 \mathrm{~A} 25 \mathrm{DBDBC} 0 \mathrm{CC} 3705 \mathrm{~A} 2890$ ? sequence $=2$

OXFAM International. «Los milmillonarios del mundo poseen más riqueza que 4600 millones de personas». Acceso: 30 de agosto de 2021.

https://www.oxfam.org/es/notas-prensa/los-milmillonarios-del-mundoposeen-mas-riqueza-que-4600-millones-de-personas

Lloredo Alix, Luis La crisis y desmantelamiento del Estado de derecho: de derechos a privilegios. Revista Papeles de relaciones ecosociales y cambio global. Núm. 124 2013/14, 37-51.

https://www.researchgate.net/profile/Luis-Lloredo-

Alix/publication/269634423_La_crisis_y_el_desmantelamiento_del_Estado _de_Derecho_de_derechos_a_privilegios/links/5490ab010cf2 14269f $27 \mathrm{~d} 367 /$ La-crisis-y-el-desmantelamiento-del-Estado-de-Derecho-de-derechos-aprivilegios.pdf?origin=publication_detail

PEN-CONARE. Estado de la Nación en desarrollo sostenible, 2017. Recuperado de https://estadonacion.or.cr/informes/\#

Ugarte Jiménez, Óscar. «Sectores sociales y empresariales se enfrentan por manejo privado de Ebais». Semanario Universidad. 14 de noviembre de 2020. Acceso: 30 de agosto de 2021.

https://semanariouniversidad.com/pais/sectores-sociales-y-empresariales-seenfrentan-por-manejo-privado-de-ebais/ 